\title{
Prevention of postpartum Hemorrhage with Sublingual Misoprostol or Oxytocin
}

\begin{abstract}
Postpartum hemorrhage is a life threatening situation and one of the important causes of maternal mortality and morbidity, worldwide. To evaluate the effectiveness of a low dose (400ug) of misoprostol administrated sublingually compared to $10 \mathrm{IU}$ of intramascular oxytocin for the reduction of postpartum blood loss. A total of 120 patients were randomized to receive either $400 \mu \mathrm{g}$ misoprostol sublingually or $10 \mathrm{IU}$ oxytocin intramuscularly after vaginal delivery. Primary outcome measured was mean blood loss and incidence of primary postpartum hemorrhage (PPH). Secondary outcome measured included change in pre and 24 hour post-delivery hemoglobin and hematocrit values, side effects of the used drugs, and the need for blood transfusion. Results: Although not statistically significant, mean blood loss mean in misoprostol group $(301.92 \pm 132.95)$ was lower than in oxytocin group $(317.58 \pm 120.12)$. Incidence of postpartum hemorrhage was $(1.7 \%)$ in misoprostol group versus in oxytocin group $(3.3 \%)$. We observed that $6.7 \%$ and $8.3 \%$ of women experienced a hemoglobin decline of $>10 \% 24$ hours after receiving misoprostol and oxytocin, respectively $(p=$ $1.0)$, the mean of HCT drop in misoprostol group $(3.43 \pm 2.8)$ and $(3.38 \pm 2.92)$ in oxytocin group $(p=0.92)$. Side effects were significantly greater in the misoprostol group than in the oxytocin group. Conclusion: Although not statistically significant, $400 \mathrm{ug}$ of sublingual misoprostol is more effective than $10 \mathrm{IU}$ of oxytocin administrated via the intramuscular route in reducing post delivery blood loss.
\end{abstract}

Keywords: Misoprostol, Oxytocin, Postpartum hemorrhage.

\section{Introduction}

Postpartum hemorrhage (PPH) is a life threatening situation and one of the important causes of maternal mortality and morbidity, worldwide [1]. Postpartum hemorrhage (PPH) has been defined as a bleed of 500 $\mathrm{ml}$ or more in vaginal deliveries and in excess of 1000 $\mathrm{ml}$ in abdominal deliveries and is usually based on subjective observations [2]. Uterine atony is the most common cause of PPH which contributes to $80 \%$ of cases of PPH [3].

Active management of the third stage of labour, particularly Prophylactic administration of uterotonic agents could significantly reduce the rate of postpartum hemorrhage from $18 \%$ to $5 \%$ compared with that of expectant management [5].

The most ideal uterotonic agent for the active management of third stage of labor has been the subject of research. However, intramuscular $10 \mathrm{IU}$ of oxytocin remains the standard of care by the World Health Organization (WHO) recommendation [6,7]. Despite the preference for oxytocin, it is not always feasible to administer oxytocin in economically challenged environment, given its requirement for cool storage [7]. Carbetocin which is more room temperature stable than oxytocin, it also requires skilled personnel for parenteral administration and sterile equipment like oxytocin [8]. The use of oxytocin and other parenteral uterotonics is often restricted to urban centers. Misoprostol, a PGE1 analogue, has been used both for prevention and management of PPH due to its strong effect on the uterus; however, there is no consensus on optimal dose or route of administration [9]. Ease of administration and storage with the background of its effectiveness, favors the use of misoprostol in communities of resource poor settings [10] .

In the majority of these studies, misoprostol has been administered either orally or rectally in dosages ranging from $400 \mathrm{ug}$ to $1000 \mathrm{ug}$ [11].

A few studies are now available for the use of sublingual misoprostol in the prevention of blood loss following vaginal delivery and have reported its effectiveness and convenient route of administration [12].

\section{Material and methods}

This study was conducted at Benha university maternity unit and the emergency unit of the Department of Obstetrics and Gynecology, Benha Teaching Hospital, through the period started from May 2019 to December 2019. The study was applied on 120 candidates randomly into two groups, achieve the inclusion and exclusion criteria. The study protocol was approved by the Local Ethics Committee and written informed consent was taken from each patient before beginning the study.

After exclusion of the following risk factors: medical disorder as diabetes mellitus, hypertension or blood disorders, still birth, contraindication to prostaglandin therapy (history of severe bronchial asthma or allergy to misoprostol), antepartum hemorrhage. One hundred twenty patient with a singleton pregnancy at $>28$ weeks of gestation, with cephalic presentation, anticipating a normal spontaneous vaginal delivery (including episiotomy), and with haemoglobin $>9 \mathrm{~g} / \mathrm{dl}$ upon presentation, who were admitted to the labour room All patients were subjected to full history taking, general, abdominal and 
obstetric examination. Ultrasound scan, complete blood picture, liver functions and coagulation profile were also done.

The sample size was calculated using Cochran formula " $\mathrm{n} 0=(\mathrm{Z}$ square $\mathrm{x}$ pq/e square $)$ "

The patients included in this study were divided randomly into two groups : First group:- sixty women received $400 \mathrm{ug}$ of sublingual misoprostol within one minute of cord clamping. Second group:- sixty women were injected intramuscularly by $10 \mathrm{IU}$ oxytocin within one minute of cord clamping.

All participants were followed-up for $24 \mathrm{~h}$. The uterine tone and amount of bleeding were noted and the need for further uterotonic agents was checked. Also the need for blood transfusion and ocurrence of drugs side effects were observed. Blood loss was measured using a plastic drape for blood collection (the BRASSSV Drape), which was placed under the buttocks before delivery; the calibrated blood collection receptacle was however opened only after delivery of the baby, clamping and cutting of the cord and drainage of amniotic fluid. Blood was collected for 1 hour but careful surveillance for further bleeding was put in place till 24 hours after delivery. Additional oxytocics were used when subsequent blood loss was adjudged excessive. The blood collected in the receptacle was visually noted and also transferred to a measuring jar and volume noted. Dry weight of all swabs that were used during the third stage were measured and noted. Blood soaked swabs were weighed and the dry weight of the swabs was subtracted in grams. Assuming an equivalence of $1 \mathrm{~g}$ to $1 \mathrm{ml}$, this volume was added to the volume of blood from the BRASSS-V drape. Participation in the study ended at discharge from the facility, weighing the swabs the blood collected into drapes under the patients' buttocks was transferred to a measuring jar and measured in milliliter. PPH was defined as bleeding $\geq 500 \mathrm{ml}$. Blood hemoglobin and hematocrit were assessed $24 \mathrm{~h}$ after delivery. We recorded possible complications like nausea, vomiting, abdominal pain, flushing, tachycardia, hypotension, headache, itching, metallic taste.

Data were statistically described in terms of mean \pm standard deviation $( \pm \mathrm{SD})$, or frequencies (number of cases) and percentages when appropriate. Comparison of numerical variables between the study groups was done using inde pendent t-test. For comparing categorical data, Chi square (z2) test was performed. Exact test was used instead when the expected frequency is less than $5 . \mathrm{p}$ values less than 0.05 were considered statistically significant. All statistical calculations were done using computer program SPSS (Statistical Package for the Social Science; SPSS Inc., Chicago, IL) release 15 for Microsoft Windows (2006).

\section{Results}

Baseline characteristics of the groups are summarized in Table (1). There was no significant difference between the groups in age, parity, body mass index, gestational age, fetal birth weight.

The amount of bleeding and occurrence of PPH were lower in the misoprostol group; however it was not statistically significant Table (2). The drop of hemoglobin by $10 \%$ and hematocrit drop 24 hour after delivery compared to pre delivery were lower in the misoprostol group, but they were not of a statistically significant difference Table (3).

There was no significant difference between the two groups regarding need for other uterotonics ;however it was slightly increased in the oxytocin group Table (4)

Regarding drugs side effects, mild shivering was highly significant in the misoprostol group Table (5).

Table (1) Demographic and characteristic data of participants.

\begin{tabular}{|c|c|c|c|c|}
\hline \multirow{2}{*}{$\begin{array}{l}\text { Base line - birth } \\
\text { related characters }\end{array}$} & Oxytocin group (60) & Misoprostol group (60) & \multirow{2}{*}{$\begin{array}{l}\text { Statistical } \\
\text { test }\end{array}$} & \multirow{2}{*}{$\begin{array}{l}\mathrm{P} \\
\text { value }\end{array}$} \\
\hline & No & No & & \\
\hline $\begin{array}{l}\text { Age mean } \pm \text { SD } \\
\text { Parity }\end{array}$ & $30.83 \pm 8.36$ & $30.57 \pm 8.41$ & St $\mathrm{t}=0.17$ & 0.86 \\
\hline Nulli-para & $48.3 \%$ & $45.0 \%$ & $\mathrm{X} 2=0.13$ & 0.71 \\
\hline Multi-para & $51.7 \%$ & $55.0 \%$ & & \\
\hline BMI mean \pm SD & $28.0 \pm 4.79$ & $28.28 \pm 4.87$ & St $\mathrm{t}=0.32$ & 0.75 \\
\hline $\begin{array}{l}\text { GA median } \\
(\mathrm{IQR})\end{array}$ & $35.08(30.75-38.71)$ & $37.22(33.11-39.14)$ & $\mathrm{Z}=1.87$ & 0.062 \\
\hline $\begin{array}{l}\text { Birth weight mean } \\
\pm \text { SD }\end{array}$ & $2591.5 \pm 882.4$ & $2830.33 \pm 785.7$ & St $\mathrm{t}=1.57$ & 0.12 \\
\hline
\end{tabular}

Table (1) shows no significant statistical differences between the misoprostol and oxytocin groups for all demographic variables. 
Table (2) comparing the estimated blood loss and the occurrence of postpartum haemorrhage between the two groups

\begin{tabular}{lcccc}
\hline & Oxytocin group (60) & Misoprostol group (60) & $\begin{array}{c}\text { Statistical } \\
\text { test }\end{array}$ & P value \\
\hline $\begin{array}{l}\text { Estimated blood loss } \\
\text { mean } \mathbf{~ S D ~}\end{array}$ & $317.58 \pm 120.12$ & $301.92 \pm 132.95$ & St t $=0.68$ & 0.50 \\
$\begin{array}{l}\text { PPH N }(\%) \\
\geq \mathbf{5 0 0} \text { ml }\end{array}$ & $2(3.3 \%)$ & $1(1.7 \%)$ & FET $=0.0$ & 1.0 \\
\hline
\end{tabular}

Although mean blood loss and the incidence of postpartum haemorrhage in misoprostol group were less than in oxytocin group; there was no statistically significant difference between them.

Table(3) Comparison between the two groups regarding drop in HB and HCT occurring 24 hours after delivery.

\begin{tabular}{lcccc}
\hline Investigations & $\begin{array}{c}\text { Oxytocin } \\
\text { group }(\mathbf{6 0})\end{array}$ & $\begin{array}{c}\text { Misoprostol group } \\
(\mathbf{6 0 )}\end{array}$ & Statistical test & P value \\
\hline HB drop > 10\% N (\%) & $5(8.3 \%)$ & $4(6.7 \%)$ & FET $=0.0$ & 1.0 \\
HCT drop mean \pm SD & $3.38 \pm 2.92$ & $3.43 \pm 2.8$ & St t $=0.096$ & 0.92 \\
\hline
\end{tabular}

There was no significant difference in the decrease in hematocrit and hemoglobin drop between the two groups.

Table (4) Additional requirements of uterotonics for the patients in misoprostol and oxytocin groups.

\begin{tabular}{|c|c|c|c|c|c|c|}
\hline Requirement of & Oxyt & up $(60)$ & Misop & oup $(60)$ & Statistical & P value \\
\hline $\begin{array}{l}\text { additional uterotonic } \\
\text { medication }\end{array}$ & No & $\%$ & No & $\%$ & test & \\
\hline Present & 6 & $10.0 \%$ & 1 & $1.7 \%$ & $\mathrm{FET}=2.43$ & 0.12 \\
\hline
\end{tabular}

Table (4) shows an increased need for uterotonic drugs in oxytocin group. However, it was of no statistical significance.

Table (5) Comparison between two groups as regards maternal adverse effects and their statistical difference.

\begin{tabular}{lcccccc}
\hline Side effects & \multicolumn{2}{c}{ Misoprostol group (60) } & \multicolumn{2}{c}{ Oxytocin group (60) } & Statistical & P value \\
\cline { 2 - 5 } & No & \% & No & \% & test & \\
\hline Shivering & & & & & & \\
Mild & 9 & 15.0 & 0 & 0.0 & FET $=7.69$ & $0.003^{* *}$ \\
Severe & 3 & 5.0 & 1 & 1.7 & FET $=0.26$ & 0.62 \\
Fever & 5 & 8.3 & 0 & 0.0 & FET $=3.34$ & 0.057 \\
Vomiting & 1 & 1.7 & 2 & 3.3 & FET $=0.0$ & 1.0 \\
Tachycardia & 2 & 3.3 & 0 & 0.0 & FET $=0.51$ & 0.50 \\
Nausea & 2 & 3.3 & 0 & 0.0 & FET $=0.51$ & 0.50 \\
Diarrhea & 1 & 1.7 & 1 & 1.7 & FET $=0.0$ & 1.0 \\
\hline
\end{tabular}

Table (5) shows highly significant statistical difference between the two groups regarding mild shivering; there was no statistical significant difference regarding other side effects

\section{Discussion}

Our study showed no significant difference in demographic data in relation to age, parity, gestational age between both groups.

The studied patients underwent normal vaginal delivery. The volume of blood loss, pre delivery \& 24 hour post delivery HB and HCT are registered. Drugs side effects within 6 hours after delivery and the additional need for uterotonics or blood transfusion were observed In this study, Blood loss in oxytocin group was $(317.58 \pm 120.12)$, and in misoprostol group
(301.92 \pm 132.95$)$. So the estimated blood loss in misoprostol group was lower than the estimated blood loss in oxytocin group. However it was not statistically significant. The incidence of postpartum hemorrhage (blood loss $\geq 500 \mathrm{ml}$ ) was $2 \%$ in oxytocin \& $1 \%$ in misoprostol. There is no statistically significant difference between both groups regarding postpartum hemorrhage.

Our study showed that there were no significant difference between the two groups in terms of the 
predelivery and 24 hour postdelivery HB \& HCT values.

Our results agree with the study conducted by Othman et al where it concluded that a dose of $400 \mathrm{ug}$ of sublingual misoprostol is more effective than intravenous infusion of 20 units of oxytocin. The study included 120 women scheduled for elective cesarean delivery. The study found The overall mean blood loss was significantly lower in the misoprostol group compared to the oxytocin group $(490.75 \pm 159.90 \mathrm{~mL}$ vs. $601.08 \pm 299.49 \mathrm{~mL} ; \mathrm{p}=0.025)$. However, changes in hematocrit level (pre- and postpartum) was comparable between both groups. There was a need for additional oxytocic therapy in $16.7 \%$ and $23.3 \%$ after use of misoprostol and oxytocin, respectively ( $\mathrm{p}=$ 0.361 ). Incidence of side effects such as shivering and metallic taste were significantly higher in the misoprostol group compared to the oxytocin group ( $\mathrm{p}<$ 0.001) [13]

Our study also agrees with the study of Rajaei et al., in a double-blind randomized controlled trial, in which 400 pregnant women who had a vaginal delivery were assigned into two groups: to receive either $20 \mathrm{IU}$ of oxytocin in $1000 \mathrm{~mL}$ Ringer's solution and two placebo tablets or $400 \mathrm{ug}$ oral misoprostol (as two tablets) and 2 $\mathrm{mL}$ normal saline in $1000 \mathrm{~mL}$ Ringer's solution. The quantity of blood loss was higher in the oxytocin group in comparison to the misoprostol group. There was no significant difference in the decrease in hematocrit and hemoglobin between the two groups. The patients in the oxytocin group had greater need for additional oxytocin. [14]

Our study also agrees with the study by Bellad et al where 652 consenting eligible pregnant women admitted to the labour room, received either $400 \mathrm{ug}$ powdered sublingual misoprostol or standard 10 IU intramuscular (IM) oxytocin. The study concluded that sublingual misoprostol more effective than intramuscular oxytocin in reducing postpartum hemorrhage, with only transient side effects being greater in the misoprostol group. The sublingual mode and/or powdered formulation may increase the effectiveness of misoprostol, and render it superior to injectable oxytocin for the prevention of postpartum hemorrhage. [15]

The study of Owonikoko et al stated that blood loss was slightly lower in the misoprostol group than oxytocin group, however, this difference was not statistically significant. [16]

Meanwhile, the studies of Kundodyiwa et al, Gupta, Vimala et al, Acharya et al, Baskett et al, Winikoff et al and Blum et al concluded that sublingual/oral misoprostol has similar efficacy to oxytocin in the active management of third stage of labor regarding estimated blood loss, taking into consideration the different doses and routes of administration. [17-23]
However, our study disagrees with the study of Owa et al where a total of 104 women with term pregnancy were randomized to receive either $200 \mu \mathrm{g}$ misoprostol sublingually or 10 IU oxytocin intramuscularly after vaginal delivery. The mean blood loss with sublingual misoprostol was more than with the oxytocin group suggesting better efficiency of oxytocin ;Though overall blood loss with oxytocin was less, suggesting better efficacy; the difference was not statistically significant. There was no significant differences between the misoprostol and oxytocin groups with regard to the incidence of PPH (19.2\% vs. $13.5 \%$ respectively; $\mathrm{P}=0.43)$. The difference between our and their results could be attributed to could be attributed to the lesser dose of misoprostol used in their study . [24]

Our study also disagrees with the study of Tewatia et al where one hundred patients with no risk factors for postpartum hemorrhage received 600 ug of misoprostol sublingually or $10 \mathrm{IU}$ of intravenous oxytocin. Mean blood loss in oxytocin group was less than in misoprostol group. They concluded that intravenous oxytocin is more effective than sublingual misoprostol in preventing postpartum hemorrhage. This may be due to the different route used in for administration (IV) of oxytocin which leads to rapid onset of action. [25]

In our study, in oxytocin group, the median of $\mathrm{HB}$ before delivery was (11.7) and 24 hour post delivery was (10.6), while in misoprostol group the median of HB before delivery was (11.5) and 24 hour post delivery was (10.5). Regarding HCT in both groups, the mean of HCT before delivery was (36.75) and 24 hour post delivery in oxytocin group was (33.37), in comparison to its mean in misoprostol group before delivery(36.28) and 24 hour post delivery(32.85). HB drop by $10 \% 24$ hours after delivery was in oxytocin group $(8.3 \%)$ and $(6.7 \%)$ in misoprostol group. Thus, comparing misoprostol and oxytocin groups; there was no significant difference in the decrease in hematocrit and hemoglobin between the two groups. The incidence of postpartum hemorrhage in oxytocin group was $(3.3 \%)$ and $(1.7 \%)$ in misoprostol group, but it was of no statistical significance. Which agrees with the following studies of Rajaei, Owa and Subedi [14,24,26]

When we tested the need for additional uterotonic drugs, there were more women in the oxytocin group who needed additional uterotonic drugs. However this difference did not reach statistical significance. This agrees with the study done by Vimala et al who compared 400 ug sublingual misoprostol with 20 iu intravenous oxytocin. Our findings differ from those of Singh et al who found the need for additional uterotonics to be identical in women receiving $400 \mathrm{ug}$ sublingual misoprostol and $5 \mathrm{Iu}$ intravenous oxytocin. $[18,27]$

In our study postpartum shivering was a statistically significant side effect to misoprostol, $15 \%$ of patients in 
misoprostol had shivering which was mild and self limited. Also in misoprostol group $8.3 \%$ of the patients had low grade fever compared to none in the oxytocin group, which was of no statistical significant difference. This result matches the studies by Vimala, Lumbiganol and Gulmezoglu which reported that shivering and pyrexia are the main side effects of the sublingual misoprostol. Hua et al also added that misoprostol was associated with more drug related side effects than oxytocin, especially postpartum shivering/pyrexia, which was generally mild, transient, not life threatening and self limited. Although adverse effects may cause some concern regarding safety, the transient occurrence of inconsequential adverse effects may be acceptable and preferable to the consequences of primary PPH in resource limited communities[18,28,29,30] .

\section{References}

[1] H .Shakur, D .Elbourne, M .Gülmezoglu, Z. Alfirevic, C .Ronsmans, The WOMAN Trial (World Maternal Antifibrinolytic Trial): tranexamic acid for the treatment of postpartum haemorrhage: an international randomised, double blind placebo controlled trial. Tri, Vol.11(1), pp.40,2010.

[2] H.A. Mousa, J .Blum, E.l. Senoun, H. Shakur, Z .Alfirevic , Treatment for primary postpartum haemorrhage. Cochrane database of systematic reviews, Vol.5(3), pp.12-15,2014.

[3] R. Abdul-Kadir, C. McLintock, A.S. Ducloy, H. ElRefaey, A. England, Evaluation and management of postpartum hemorrhage: consensus from an international expert panel. Transfusion , Vol.54(7), pp.1756-68,2014.

[4] N .Buzaglo, A. Harlev, R. Sergienko, E .Sheiner, Risk factors for early postpartum hemorrhage (PPH) in the first vaginal delivery, and obstetrical outcomes in subsequent pregnancy. Journal of Maternal-Fetal Neonat Med, Vol.28(8), pp.932,2015.

[5] D .Leduc, V .Senikas, A.B. Lalonde, C. Ballerman, A .Biringer, Active management of the third stage of labour: prevention and treatment of postpartum hemorrhage. JOG Cana, Vol.31(10), pp.980-93,2009.

[6] WHO , Recommendations on Prevention and Treatment of Postpartum Haemorrhage. Geneva: World Health Organization,2012.

[7] M.R. Torloni, G .Freitas, U.H. Kartoglu, M. Gulmezoglu, M .Widmer, Quality of oxytocin available in low- and middle-income countries: a systematic review of the literature. BJOG , Vol.123(13), pp. 2076-2085,2016.

[8] M .Widmer, G .Piaggio, T.M.H. Nguyen, A .Osoti, O.O. Owa, Heat-stable carbetocin versus oxytocin to prevent hemorrhage after vaginal birth. N Engl J Med 2018, Vol.379, pp.743-52,2018.

[9] O .Ozkaya, M. Sezik, H .Kaya, R. Desdicioglu, R. Dittrich, Placebo-controlled randomized comparison of vaginal with rectal misoprostol in the prevention of postpartum hemorrhage. J Obstet Gynecol Res , Vol.31, pp.389-93,2005.

[10]E.O. Afolabi, O. Kuti, E.O. Orji, S.O .Ogunniyi, Oral misoprostol versus intramuscular oxytocin in the active management of the third stage of labour. Singapore Med J, Vol.51, pp.207-11,2010.

[11]F. Rizvi, R .Mackey, T .Barrett, P. Mckenna, M .Geary, Successful reduction of massive postpartum hemorrhage by use of guidelines and staff education. BJOG, Vol.111, pp.495-8,2004.

[12] World Health Organization , Geneva 7. Motherebaby package: implementing safe motherhood in countries, Vol. 94, pp. 11-24,1998.

[13]E .Othman, M. Fayez, D .Abd El Aal, H .Mohamed, A .Abbas, Sublingual misoprostol versus intravenous oxytocin in reducing bleeding during and after cesarean delivery: a randomized clinical trial. $\mathrm{T}$ Journal of Obstet Gynecol; vol. 55(6), pp.791-5,2016.

[14]M. Rajaei, S .Karimi, Z .Shahboodaghi, H. Mahboobi, T. Khorgoei, Safety and efficacy of misoprostol versus oxytocin for the prevention of postpartum hemorrhage. J Preg; vol.15(9), pp. 713$879,2014$.

[15]M.B.Bellad, A.D.Tara, M.S.Ganachari, M.D.Mallapur, S.S.Goudar, Prevention of postpartum haemorrhage with sublingual misoprostol or oxytocin: a double-blind randomised controlled trial. BJOG, Vol.119, pp.975-986,2012.

[16]K.M.Owonikoko, A.Arowojolu, M.Okunlola, Effect of sublingual misoprostol versus intravenous oxytocin on reducing blood loss at cesarean section in Nigeria: A randomized controlled trial. Journal Obstet Gynaeco Research, Vol.37(7), pp.71521,2011 .

[17]T.W.Kundodyiwa, F. Majoko, S.Rusakaniko, Misoprostol versus oxytocin in the third stage of labor. IJOG, Vol.75 (3), pp. 235-41,2001.

[18]N.Vimala, S.Mittal , S.Kumar ,Sublingual misoprostol versus oxytocin infusion to reduce blood loss at cesarean section. IJOG, Vol.92(2), pp.106-10,2006.

[19]T.F.Baskett, Acute uterine inversion: a review of 40 cases. JOG Cana, Vol.24 (12), pp.953-6,2002.

[20]M.Widmer, J.Blum, G.J.Hofmeyr, G.Carroli, H.Abdel-Aleem, Misoprostol as an adjunct to standard uterotonics for treatment of post-partum haemorrhage: a multicentre, double-blind randomised trial. Lancet, Vol.375 (9728), pp.180813,2010

[21]W.R.Sheldon, J.Blum, J.Durocher, B.Winikoff, Misoprostol for the prevention and treatment of postpartum hemorrhage. Exp op invest drugs , Vol.21(2), pp. 235-50,2012. 
[22]S.Gupta, Operative obstetrics, in A Comprehensive Textbook of Obstetrics and Gynecology, Jaypee Brothers Medical Publishers P Limited, Vol. 10(8), pp.563,2011.

[23]G.Acharya, M.Al-Sammarai, N.Patel, A.Al-Habib , T.Kiserud, A randomized controlled trial comparing effect of oral misoprostol and intravenous syntocinon on intra -operative blood loss during cesarean section. Acta Obstet Gynecol Scand, Vol.80(3), pp.245-50,2004.

[24]O.O.Owa, A.S.Lemadoro, B.A.Temenu, J.A.Ayeyemi, O.M.Loto ,Misoprostol versus oxytocin in preventing postpartum hemorrhage: A randomized controlled trial. Trop J Obstet Gynaecol, Vol.36, pp.196-9,2019.

[25]R.Tewatia, S.Rani, U.Srivastav, B.Mukhija, Sublingual misoprostol versus intravenous oxytocin in prevention of postpartum hemorrhage. Arch Gynecol Obstet, Vol.289(4), pp.739-742,2014.
[26]N.Subedi, D.Sharma, R.Das, Comparison of misoprostol with oxytocin in third stage of labour. Journal U C of Med Sci, Vol.6(1), pp.19-21,2018.

[27]G.Singh, G.Radhakrishnan, K.Guleria, Comparison of sublingual misoprostol, intravenous oxytocin, and intravenous methlyergometrine in active management of the third. Obstet Gynaecol, Vol.107(2), pp.130-4,2009.

[28]J.Lumbiganol Pisake, Hofmeyr, M.Gilmezoglu, A.Pinol , J.Villar, Misoprostol dose- related shivering and pyrexia in the third stage of labor. $\mathrm{Br}$ J Obstet Gynecol, Vol.106(4), pp. 304-8,1999.

[29]A.M.Gulmezoglu， J.Villar， N.T.N.Ngoc，WHO multicentre randomized trial of misoprostol in the management of the third stage of labour. Lancet, Vol.358(9283), pp.689-95,2011.

[30]J .Hua, Effect of misoprostol versus oxytocin during caesarean section: a systematic review and meta-analysis. BJOG, Vol.120(5), pp.531540,2001 